\title{
Modelling of A Boundary Layer Ingesting Propulsor
}

\author{
Nils Budziszewski * and Jens Friedrichs \\ Institute of Jet Propulsion and Turbomachinery, TU Braunschweig, Hermann-Blenk-Straße 37, \\ D-38108 Braunschweig, Germany; j.friedrichs@ifas.tu-braunschweig.de \\ * Correspondence: n.budziszewski@ifas.tu-braunschweig.de; Tel.: +49-531-391-66661
}

Received: 3 February 2018; Accepted: 19 March 2018; Published: 21 March 2018

\begin{abstract}
Boundary layer ingestion is a promising method to decrease the propulsive power consumption of an aircraft, and therefore the fuel consumption. This leads to a reduced environmental impact and an improved cost-efficiency. To get a better understanding of this method and to estimate its benefits, the modelling of a propulsor located at the upper rear centerbody of a blended wing body aircraft is presented in this paper. A parallel compressor model approach is used to analyse the impact of the ingested low velocity fluid which leads to a non-uniform inflow. The required boundary layer data are generated with an analysis tool for 2D subsonic airfoils. Some parameter variations are conducted with the developed programme to study their impact on the power saving potential. In addition, a simple estimation for the benefit of embedded aeroengines is given. Despite the drawback from fan efficiency due to the inflow distortion, the results show a significant decrease in required propulsive power for boundary layer ingestion in combination with integrated engines.
\end{abstract}

Keywords: boundary layer ingestion; parallel compressor model; propulsion; embedded aeroengine

\section{Introduction}

Modern aircraft design and aeroengine development is driven by the attempt to increase the overall efficiency of the transport system, which results in reduced fuel burn and, consequently, lower emissions and costs. For the European air traffic sector the economic and environmental goals are worded in papers such as ACARE (Advisory Council for Aeronautics Research in Europe) Vision 2020 [1] and Flightpath 2050 [2]. Over the years, the targets for $\mathrm{CO}_{2}$ and $\mathrm{NO}_{X}$ reduction are getting stricter and the effort to achieve them has to be increased. One ambition of the interdisciplinary research project Energy System Transformation in Aviation (EWL (German: Energiewende in der Luftfahrt)) initiated by the Aeronautics Research Center Niedersachsen is to identify promising new technologies for civil transport aircraft and to conduct preliminary studies in order to enable the fulfilment of the requested emission reduction targets. The propulsion system is one of the parts that have to be improved to reduce the fuel consumption of modern aircraft. Since it is a mature technology, new concepts such as boundary layer ingestion (BLI), which is closely connected to embedded engines, have to be taken into account to get a relevant benefit. Previous studies in this field revealed a promising potential for all kinds of aircraft concepts [3-7] and encouraged the present work. The intention was to develop a fast tool for basic performance analyses of a single propulsor in the presence of BLI and it should be decoupled from a concrete aircraft design. In the following sections this method for modelling a BLI propulsor is presented and the results of a preliminary study are shown to give a first overview of the sensitivities of BLI and embedded aeroengines. 


\section{Theoretical Background}

\subsection{Boundary Layer Ingestion}

Boundary layer ingestion is a widely known method to reduce the propulsion power consumption of an aeroengine. The basic idea is to use an inflow with the lowest velocity possible for thrust generation to minimize the required propulsion power for the necessary thrust. Equations (1) and (2) show a simple way to calculate the thrust and propulsive power of an aeroengine by taking only the momentum and kinetic energy at in- and outlet into account.

$$
\begin{aligned}
& T=\dot{m} \cdot\left(v_{\text {out }}-v_{\text {in }}\right) \\
& P=\frac{1}{2} \cdot \dot{m} \cdot\left(v_{\text {out }}^{2}-v_{\text {in }}^{2}\right)
\end{aligned}
$$

For better understanding, an exemplary solution of the two equations is shown in Figure 1. It can be clearly seen that the necessary propulsive power is reduced for decreasing inlet velocities. Since the propulsive power is representative for the fuel consumption, a reduction means lower fuel burn and therefore a more efficient engine.

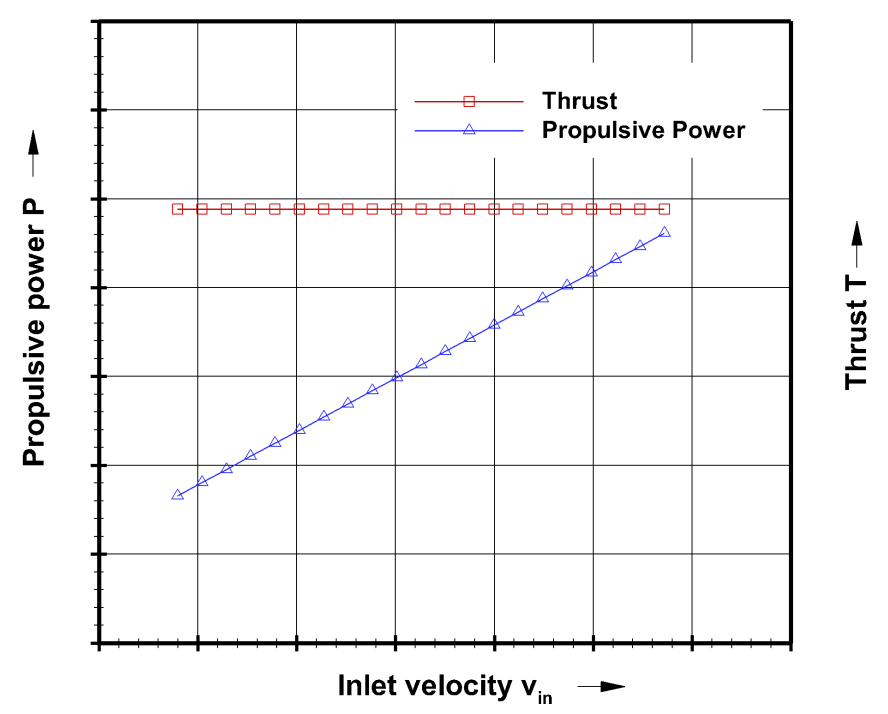

Figure 1. Necessary power for a constant thrust at varying inlet velocities.

To assess the effectivity of boundary layer ingestion a power saving coefficient (PSC) defined with Equation (3) is used. The concept of a PSC was first introduced in [8]. It describes the difference in necessary propulsive power for a propulsor without boundary layer ingestion compared to one with ingestion which provides the same amount of thrust.

$$
P S C=\frac{P_{\text {no BLI }}-P_{\text {BLI }}}{P_{\text {no BLI }}}
$$

The boundary layer ingestion can be divided into two categories: full annular BLI (BLI $\left.\mathrm{BA}_{\mathrm{FA}}\right)$ and

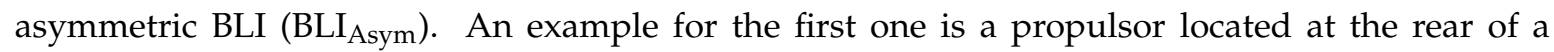
conventional aircraft sucking in the boundary layer which develops along the fuselage (Figure 2a). Thus, there are only slight deviations in the inflow conditions in circumferential direction at a constant operating point which enables the directed design of an efficient fan.

Asymmetric BLI, which is dealt with in this paper, can be found at an integrated propulsor, e.g., at the top of a blended-wing-body aircraft design (Figure 2b). It faces a more complex and challenging 
situation as there is an asymmetric inlet flow due to the boundary layer at the lower part of the propulsor. This distorted sector leads to a cutback in fan efficiency and therefore to a reduced power saving potential. A first step in analysing these non-uniform inflow conditions is the use of a parallel compressor model (described in Section 2.2).

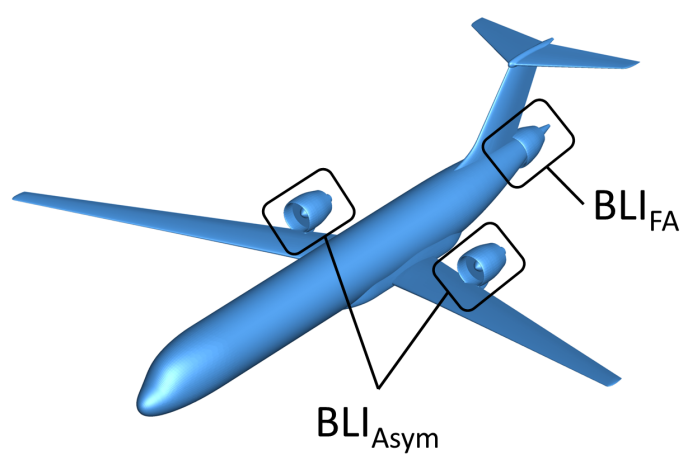

(a)

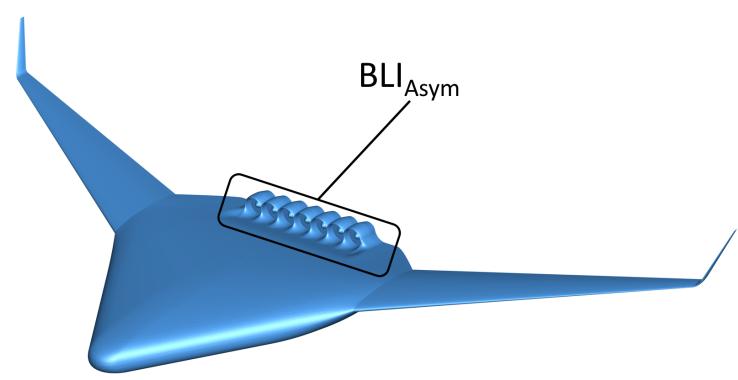

(b)

Figure 2. EWL aircraft concepts for medium and long range. (a) EWL medium range concept with rear mounted BLI propulsor; (b) EWL-BWB Concept featuring asymmetric BLI.

Many studies regarding asymmetric BLI have been conducted in the past. Bauhaus Luftfahrt estimated the BLI benefit of different aircraft concepts and determined a PSC of up to $5.66 \%$ for a blended wing body with top mounted engines [3]. The estimation based on system studies which did not account for drawbacks from fan efficiency, e.g., presented in [4]. In the same publication a more realistic approach considering fan interaction with inlet distortion showed the same trend of PSC for different amounts of ingested boundary layer. However, the benefit was lower: the analysis of the BWB developed for the Cambrigde-MIT Silent Aircraft Initiative (SAX40) resulted in a PSC of up to four percent. A similar value is reported in [5] for a BWB derived from the SAX40 aircraft. On the experimental side, the investigations with the model of the D8 aircraft (double bubble) have to be mentioned. It features a fuselage consisting of two tubes with two rear mounted engines sucking in approximately the upper half of the boundary layer. Preliminary experimental results presented in [6] showed a propulsive power reduction of six percent. This PSC value was deduced from the electrical power consumption of the model engines at a simulated cruise point. Recently published data based on the mechanical flow power gave an even higher PSC of $8.6 \%$ for the same cruise conditions [7].

\subsection{Parallel Compressor Model}

The basic idea of a parallel compressor model is to substitute a compressor which encounters inflow distortion with two identical hypothetical compressors working at different operating points [9-11]. The operating characteristic of the two subcompressors matches the undistorted original characteristic. With the help of the schematic shown in Figure 3, the concept of the parallel compressor model can be explained.

On the left side, the inflow situation with a non-uniform velocity profile resulting in a total pressure deviation is depicted. It is separated into two uniform profiles representing the different velocities (middle part of the schematic). The upper central depiction represents the undistorted part of the inflow, the lower one describes the distorted sector of the compressor. Due to the higher velocity, the corrected mass flow in the free flow region is higher than in the part of the compressor facing the disturbance. This leads to an operating point on the right side of the characteristic whereas the reduced corrected mass flow caused by the distortion results in an operating point on the left side. To deduce a single operating point, the area-weighted mean value has to be calculated (Equation (4)) [11]. In 
the given equation, $\phi$ has to be replaced with the quantity of interest, e.g., pressure ratio or efficiency, and the angle $\epsilon$ defines the distorted sector. On the right side of Figure 3 a graphical solution of the parallel compressor model is illustrated. The mean operating point can be seen and it is obvious that the inflow distortion leads to a reduced mean pressure ratio and efficiency.

$$
\bar{\phi}=\phi_{\mathrm{dis}} \cdot \frac{\epsilon}{360^{\circ}}+\phi_{\mathrm{ff}} \cdot \frac{360^{\circ}-\epsilon}{360^{\circ}}
$$

Typically, the parallel compressor model is used for inlet distortions which extend across the entire engine radius in a limited sector of the fan face (Figure $4 \mathrm{~b}$ ). The thickness of the boundary layer that is ingested by the propulsor is much smaller than the engine radius, thus, it affects only a small region at the lower part of the engine (Figure 4c). However, it is supposed that the fundamental idea of the parallel compressor concept can be applied to a boundary layer ingesting fan if a representing distortion sector based on the extend of the boundary layer is created. This approach is described in Section 3.

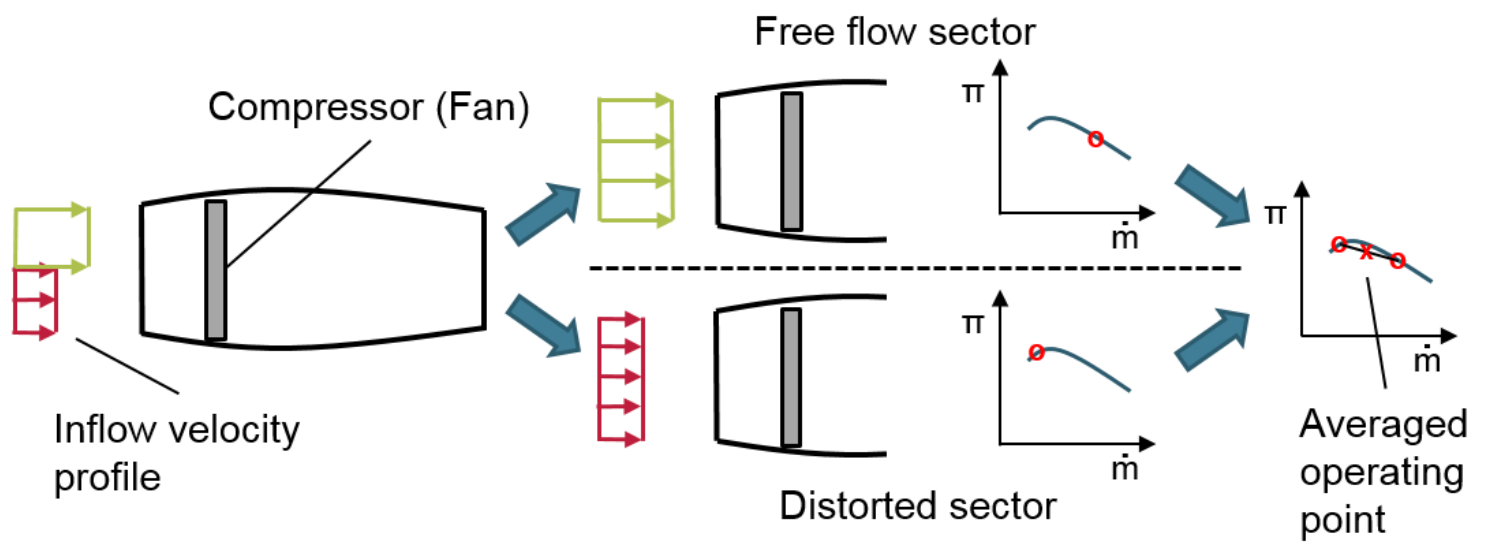

Figure 3. Functional principle of the parallel compressor model.

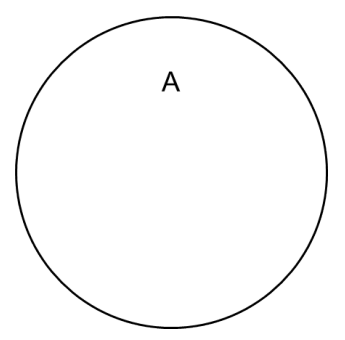

(a)

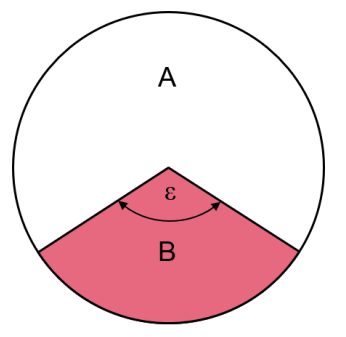

(b)

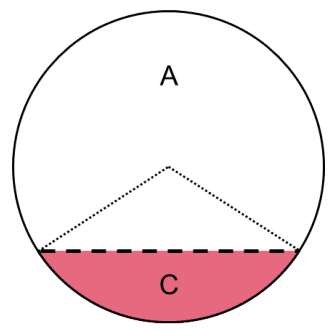

(c)

Figure 4. Different inflow situations at the fan face; A: undistorted flow, B: distorted flow, C: boundary layer. (a) Undistorted inflow; (b) Inflow with distorted sector, typical PCM application; (c) Inflow with asymmetric boundary layer.

\section{Modelling A BLI Propulsor}

To analyse the behaviour of propulsors facing asymmetric BLI, a calculation tool based on the parallel compressor concept was developed including diffusor, fan and thrust nozzle. Its main purpose is to find a solution for a given thrust requirement by modifying the pressure ratio characteristic of the fan and to compare the power demand of a boundary layer ingesting propulsor to one with uniform inflow conditions which provides the same thrust. In Figure 5 the computational domain of the process 
is illustrated. The simulation covers the whole propulsor from inlet to exit plane and is decoupled from a concrete aircraft design.

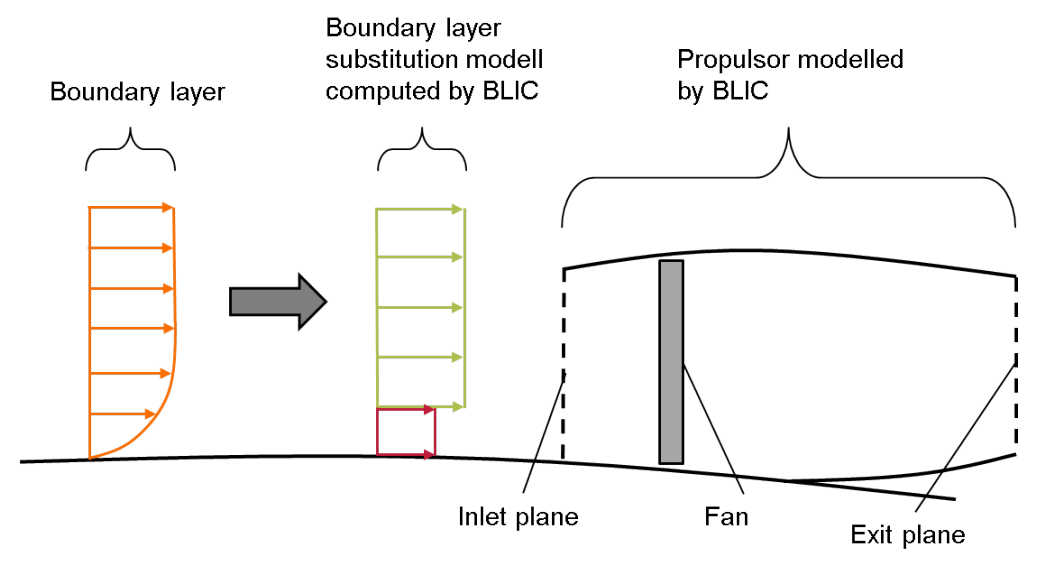

Figure 5. Simulation domain of the BLI calculation tool.

Figure 6 shows the basic process structure. The boundary layer ingestion calculator (BLIC) is controlled by a parent programme module which contains the solver configuration parameters and boundary condition values e.g., altitude, required thrust for cruise, propulsor diameter and its position in relation to the profile depth. It is possible to specify multiple sets of boundary conditions to execute the main process automatically for different input combinations. The tool is suitable for compressible, subsonic flows.

The boundary layer data, which is imported at the start of the BLIC run, is an output of XFOIL, a code released by M. Drela for design and examination of 2D subsonic airfoils [12]. To calculate the inflow conditions for the parallel compressor concept, knowledge about the velocity within the distorted sector is required. Since the XFOIL data does not contain a velocity distribution of the boundary layer, it is inevitable to generate a substitution model. In the presented process this is done using the displacement thickness $\delta^{*}$ and momentum thickness $\theta$. The goal was to represent these boundary layer parameters by a region of constant velocity $v_{\mathrm{BL}}$ and finite thickness $\delta_{\mathrm{BL}}$ in order to create an easily manageable initial situation for further calculations. Generally, the momentum thickness is defined by:

$$
\theta \cdot v_{\mathrm{E}}^{2}=\int_{0}^{\delta} v(y) \cdot\left(v_{\mathrm{E}}-v(y)\right) \mathrm{d} y
$$

Here, the variable $v_{\mathrm{E}}$ is the boundary layer edge velocity (included in the XFOIL data). Applying the integral to the described substitution model results in:

$$
\theta \cdot v_{\mathrm{E}}^{2}=\int_{0}^{\delta_{\mathrm{BL}}} v_{\mathrm{BL}} \cdot\left(v_{\mathrm{E}}-v_{\mathrm{BL}}\right) \mathrm{d} y=\delta_{\mathrm{BL}} \cdot v_{\mathrm{BL}} \cdot\left(v_{\mathrm{E}}-v_{\mathrm{BL}}\right)
$$

The displacement thickness is defined as follows:

$$
\delta^{*} \cdot v_{\mathrm{E}}=\int_{0}^{\delta}\left(v_{\mathrm{E}}-v(y)\right) \mathrm{d} y
$$




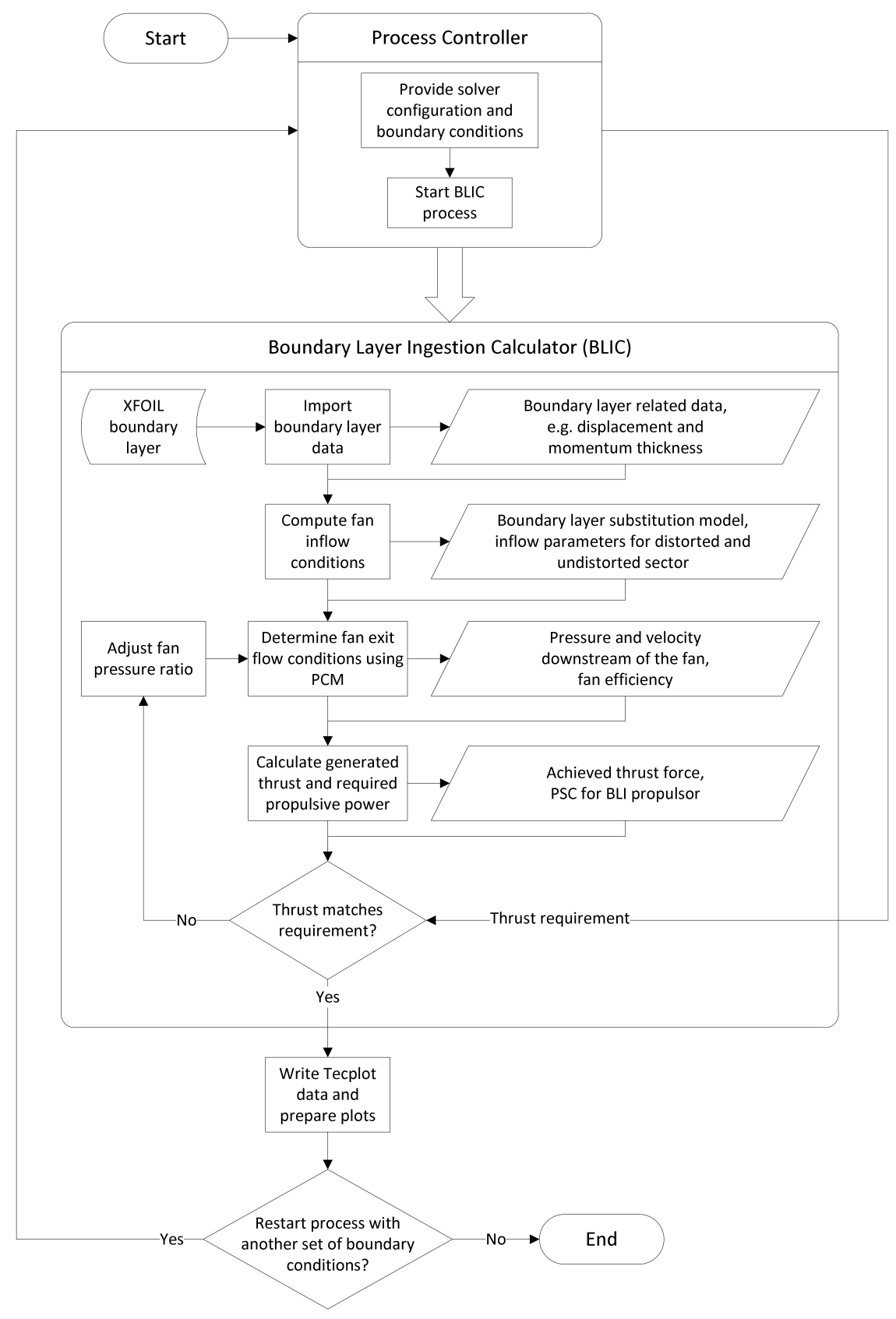

Figure 6. Process structure of BLIC.

Solving the integral for the substitution model delivers an equation for the thickness of the substitution model:

$$
\begin{aligned}
\delta^{*} \cdot v_{\mathrm{E}} & =\int_{0}^{\delta_{\mathrm{BL}}}\left(v_{\mathrm{E}}-v_{\mathrm{BL}}\right) \mathrm{d} y=\delta_{\mathrm{BL}} \cdot\left(v_{\mathrm{E}}-v_{\mathrm{BL}}\right) \\
\delta_{\mathrm{BL}} & =\frac{\delta^{*}}{\left(1-\frac{v_{\mathrm{BL}}}{v_{\mathrm{E}}}\right)}
\end{aligned}
$$

Following expression for the velocity $v_{\mathrm{BL}}$ can be derived from Equations (6) and (9):

$$
v_{\mathrm{BL}}=\frac{\theta}{\delta^{*}} \cdot v_{\mathrm{E}}
$$


Preparing the inflow conditions for the propulsor is the next step in the BLIC process. An isentropic diffusor is simulated by a reduction factor to decrease the overall velocity to a convenient level. The situation at the fan face in the presence of asymmetric BLI is depicted in Figure 7 and shows a division in two areas: the distorted sector $A_{\text {dis }}$ and the region with free flow $A_{\mathrm{ff}}$. For the undistorted area, the boundary layer edge velocity is assumed. The mean velocity of the distorted sector has to be averaged across the sector area. For this purpose, it is split into two parts. The extent of the low velocity region is determined by the boundary layer thickness $\delta_{\mathrm{BL}}$, computed for the substitution model, and the fan radius $r_{\text {Fan }}$ (Equations (11) and (12)). Just as for the free flow region, the edge velocity is assumed for the part of the distorted sector outside of the boundary layer (above the dashed line). Thus, the area-weighted mean velocity can easily be calculated.

$$
\begin{aligned}
A_{\text {dis }} & =\frac{r_{\text {Fan }}^{2}}{2} \cdot\left[\varepsilon \cdot \frac{\pi}{180^{\circ}}-\sin (\varepsilon)\right] \\
\varepsilon & =2 \cdot \arccos \left(1-\frac{\delta_{\mathrm{BL}}}{r_{\text {Fan }}}\right)
\end{aligned}
$$

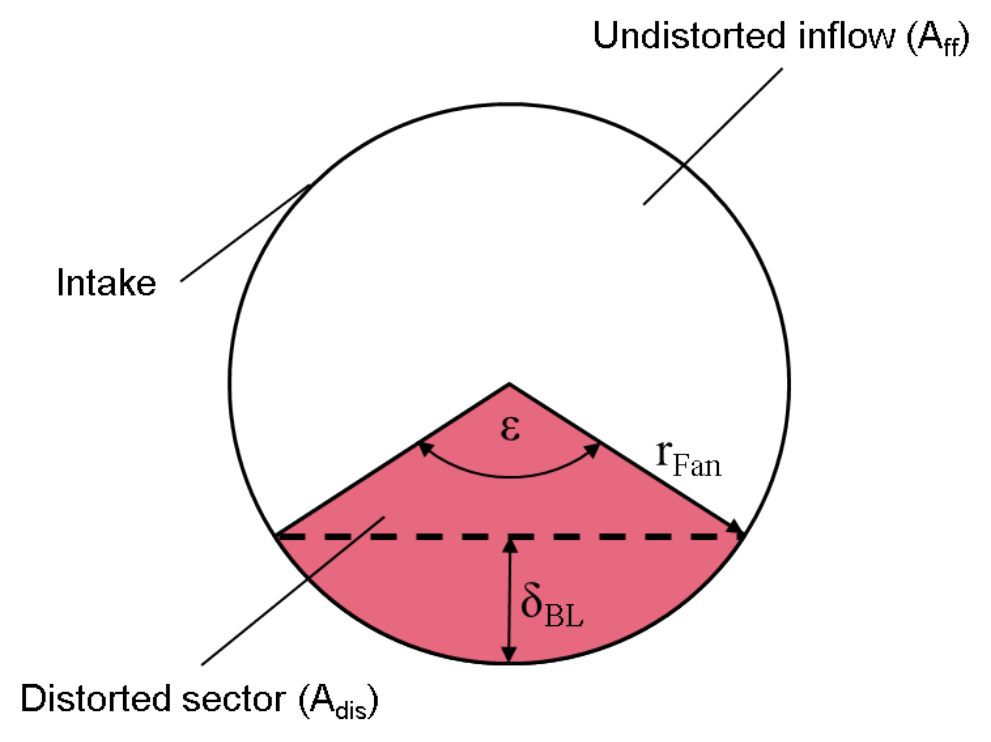

Figure 7. Front view of the inflow situation.

To determine the pressure rise across the fan and its efficiency, a parallel compressor model is implemented. It bases on a modern ultra high bypass ratio fan design which was developed and published within the Coordinated Research Centre 880 (CRC880) at the TU Braunschweig [13]. Although boundary layer ingestion was not considered during the design, the fan seems to be very appropriate for the first investigations due to the flat shape of the efficiency curve (Figure 8).

The distorted and the undistorted flow are regarded separately, no interaction takes place from inlet to the nozzle exit. With the fan tip velocity the flow coefficient $\varphi=\frac{v}{v_{\text {Tip }}}$ can be calculated to determine the two different operating points (see Figure 11 for example). Subsequently, the pressure ratio, which is evaluated for both static and total pressure, is used to compute the flow field downstream of the fan. Similar to the inlet diffusor, a simulation of an isentropic nozzle is added to the process, though, it is not represented by a factor but it is supposed to expand the pressure of the two streams to ambient conditions. The resulting exit velocities are used for thrust and propulsive power calculations according to Equations (1) and (2). To take component losses into account, the power computation is extended by the averaged fan efficiency. 


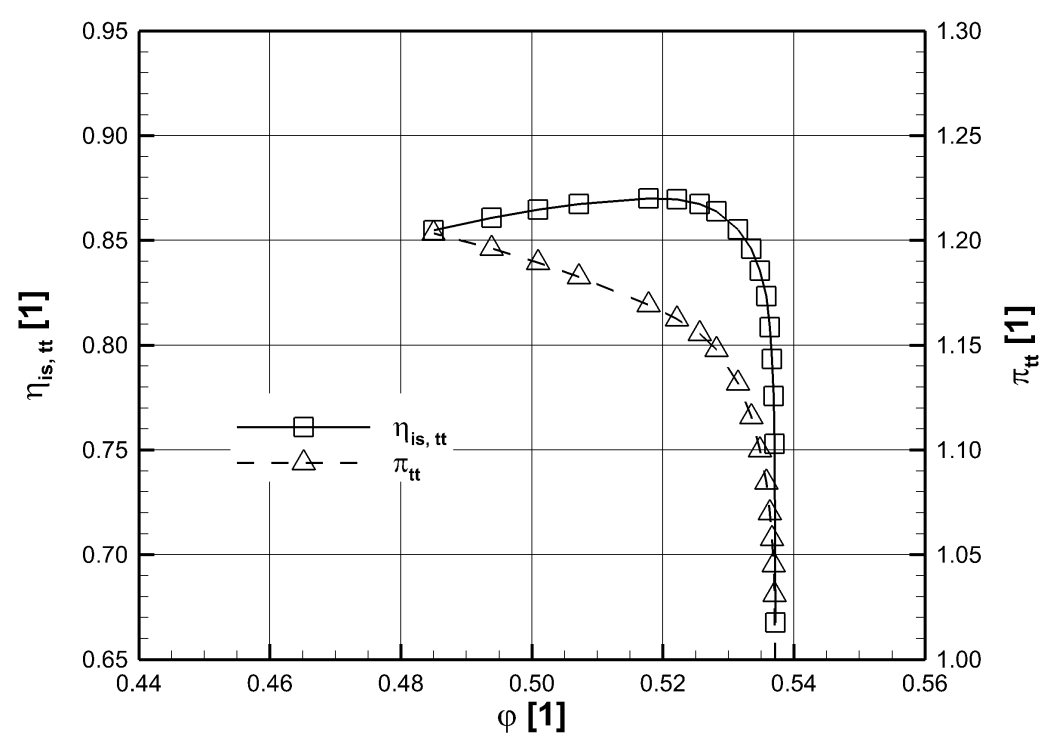

Figure 8. Fan performance.

The combined resulting thrust is then compared to the requirement and, when the deviation is smaller than $0.05 \%$, the values are considered as matching. In case the values do not match, the fan pressure ratio characteristic is modified for the next iteration. This is done by shifting the complete curve in positive or negative y-axis direction. Magnitude and direction of the offset value depend on the thrust difference. The efficiency characteristic remains untouched because it is expected that the propulsor could be redesigned to achieve a comparable performance.

Of course it is also possible to run the process without boundary layer ingestion to provide reference data for comparison. In that case no distorted sector is existent and the boundary layer edge velocity is used for the computation, which means that the application of the parallel compressor concept is omitted.

\section{Setup and First Results}

After describing the methods and modelling, the next part deals with the setup and results of the first applications of the BLIC process. The investigations presented in this paper were done with the NASA SC(2)-0518 profile (Figure 9). It is not designed for the lowest possible drag but for a large usable internal space, a parameter which is clearly very important for BWB design. With its blunt nose and remarkable $18 \%$ thickness to cord ratio, it is very suitable for a BWB cabin. For example, Lyu and Martins [14] conducted aerodynamic design optimization studies using this profile for the middle part of a BWB.

\subsection{Boundary Conditions}

The boundary conditions are summarized in Table 1. Since the cruise is the major part of a long range flight, it is the most interesting mission section for a BLI application. In addition, the angle of attack is larger at take off, climb and landing which leads to a more distinct power saving effect due to a bigger boundary layer. Hence, analysing cruise flight is a conservative approach and avoids the overrating of BLI results. According to that, the boundary conditions are chosen in such a way that they represent the cruise conditions of the BWB, which is developed in the EWL project, as close as possible with the available data. The given profile depth is representative for the BWB geometry. For the correct determination of the boundary layer, it is necessary to fix the engine inlet position. This is done with the relative engine position parameter, which defines the inlet location in relation to the 
profile depth (see Figure 9). Ambient pressure, temperature and density are determined by the altitude with the ICAO International Civil Aviation Organisation) international standard atmosphere. First parameter variations were carried out in order to study the impact of different thrust requirements (increased stepwise by $1000 \mathrm{~N}$ ), altitudes and fan radii.

Table 1. Setup and boundary conditions.

\begin{tabular}{ccc}
\hline Parameter & Unit & Value \\
\hline cruise thrust requirement & $\mathrm{kN}$ & 10 to 20 \\
upstream mach number & 1 & 0.7 \\
altitude & $\mathrm{km}$ & 13,14 and 15 \\
fan radius & $\mathrm{m}$ & $0.9,0.95$ and 1.0 \\
profile depth & $\mathrm{m}$ & 25 \\
rel. engine position & 1 & 0.9 \\
angle of attack & $\circ$ & -0.75 \\
\hline
\end{tabular}

The XFOIL computations, from which the boundary layer data come, are described by Nils Beck in [15]. He used 201 points to discretise the wing profile so that 100 panels were located on each side. As there are higher gradients (e.g., pressure distribution) at the nose of an airfoil, the points were not distributed equally spaced along the surface but denser in that region. Important for the boundary layer development is the transition from laminar to turbulent flow. To predict the transition point, an improved full $\mathrm{e}^{\mathrm{N}}$ method was applied and a critical $\mathrm{N}$-factor of 13 was used. The computations provided for this paper were carried out with a Mach number of $\mathrm{Ma}=0.7$ and a Reynolds number of $\operatorname{Re}=30 \times 10^{6}$. More detailed information regarding XFOIL, its setup parameters and the conducted computations are given in [15]. The development of the boundary layer displacement and momentum thickness along the upper side of the profile is depicted in Figure 9. The data is related to the profile depth $c$.

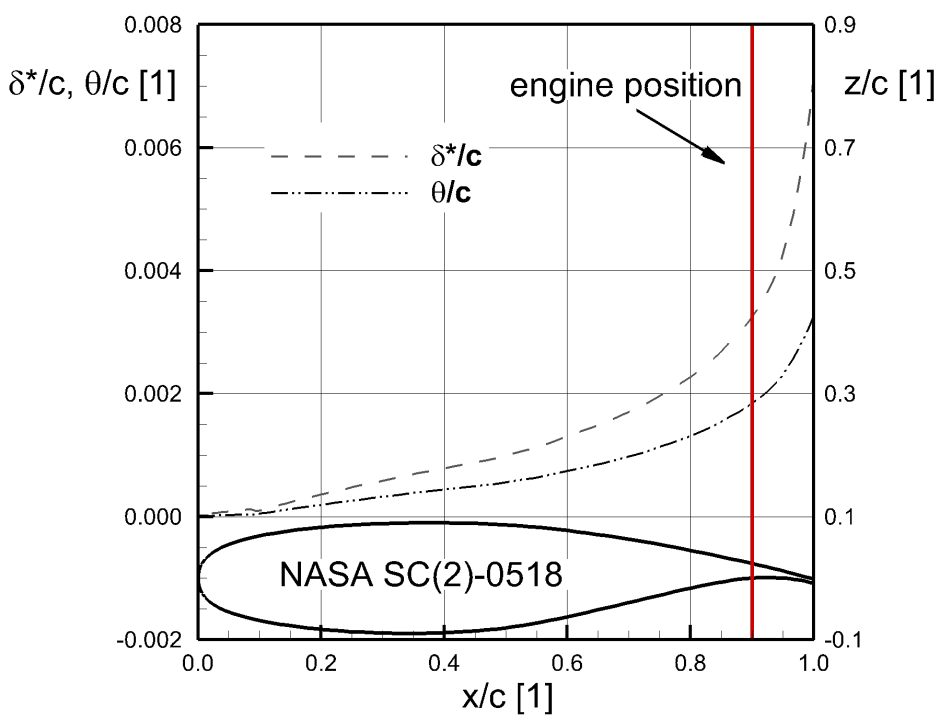

Figure 9. XFOIL boundary layer data, $\mathrm{Ma}=0.7, \mathrm{Re}=30 \times 10^{6}, \alpha=-0.75^{\circ}$.

\subsection{BLI Results}

As described above, the BLIC tool was executed for three different altitudes which lead to the results depicted in Figure 10. The power saving coefficient decreases with an increasing thrust requirement as long as any other boundary condition, especially the inlet velocity, remains unchanged. 
This is due to higher exit velocities which are necessary to fulfil the augmented thrust requirements. Since the propulsive power is proportional to the square velocity, the relative part of the boundary layer flow contributing to the power is getting smaller and, thus, the power saving potential is reduced. Looking at the different altitudes it can be seen that the PSC is lower at higher altitudes and constant thrust requirement. This effect can also be explained by a higher exit velocity which is essential to compensate for the decreasing density. However, it has to be mentioned that this comparison does not take the decreasing total drag of an aircraft for increasing altitudes into account. As drag is equivalent to thrust in this case, this would diminish the loss in PSC.

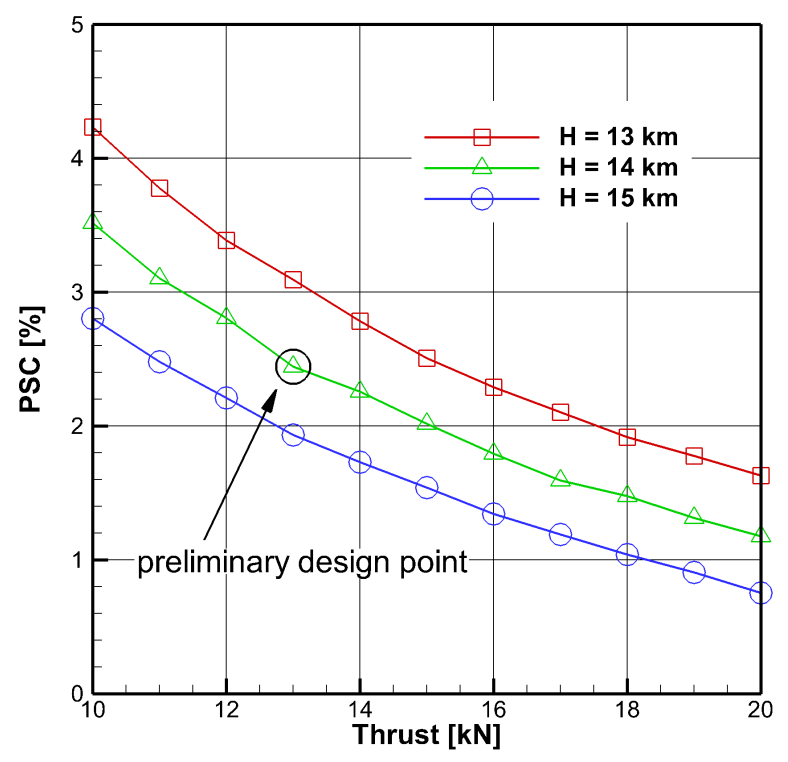

Figure 10. Power saving coefficient for varying altitudes, $r_{\text {Fan }}=0.95 \mathrm{~m}$.

Taking a closer look at a single point, the propulsor efficiency can be analysed. One engine of the baseline BWB (without any drag or weight reduction technologies) developed in the EWL project has to deliver approximately $13 \mathrm{kN}$ thrust force at cruise conditions. The flight altitude is about $14 \mathrm{~km}$. Figure 11 shows the operating points of the distorted and free flow sector as well as the averaged operating point for this preliminary design point. It reveals that the free flow sector is operating at an efficiency of $86.9 \%$, which is close to the maximum, but the efficiency of the distorted sector is only $83.7 \%$. Here it can be seen that the underlying efficiency characteristc of the parallel compressor modell does not cover the low flow coefficient of the distorted sector and it has to be extrapolated. Because of the larger free flow sector, the averaged operating point still achieves an efficiency of $86.2 \%$. This cutback in efficiency is accounted for during the PSC calculation. However, the outcome is that the configuration requires $2.44 \%$ less propulsive power than a propulsor without BLI delivering the same amount of thrust force (Figure 10).

Another interesting parameter for the boundary layer ingestion technology is the engine size. In Figure 12 the results for three different propulsor radii are shown. It is plausible that a decreasing engine size results in decreasing PSC for constant thrust requirements. First of all, again the exit velocity for a smaller engine has to be higher in order to deliver the same thrust. Additionally, the boundary layer ingesting part of the propulsor gets smaller for a reduced radius (see Equation (12)). The effect is clearly visible even for slight radius variations. Accordingly, larger propulsor diameters are preferable but it has to be kept in mind that this leads to larger nacelles and, therefore, to a drag rise. 


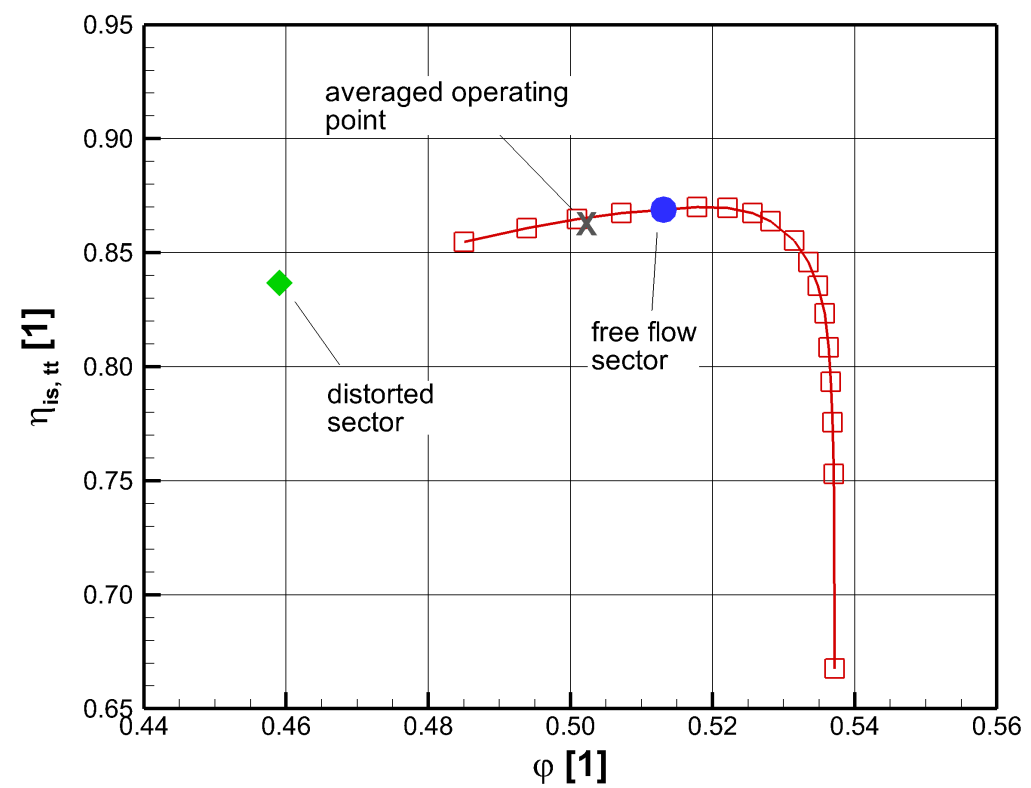

Figure 11. Operating points of the parallel compressors model at preliminary design point.

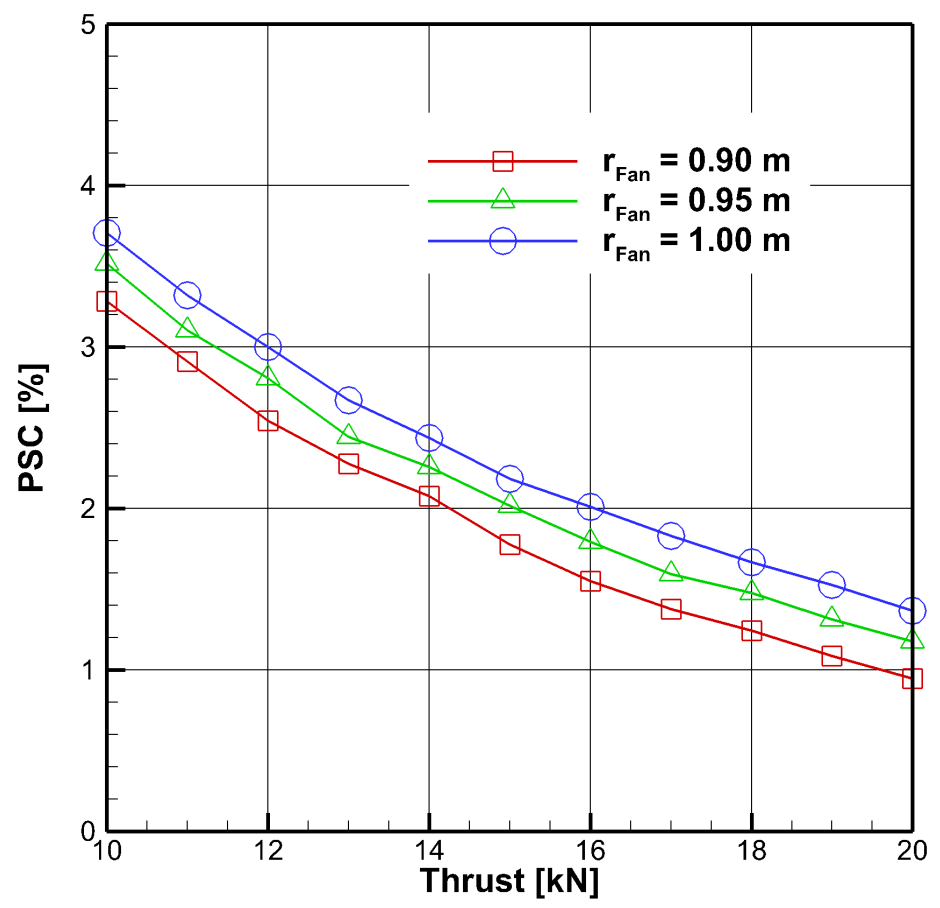

Figure 12. PSC for different engine sizes, $H=14 \mathrm{~km}$.

\subsection{Benefit of Integrated Aeroengines}

When you are dealing with boundary layer ingesting propulsors, the question arises as to how big is the benefit of integrated aeroengines, and how to assess it. To give a first estimation, a wetted area approach is used regarding the engine as a simple cylinder. Figure 13 shows the situation. The parameter $h$ defines the depth of embedment. Based on investigations presented in [16], the contribution of non-embedded engines to the total drag of an aircraft is assumed to be nine percent. 


$$
D_{\text {eng }}=0.09 \cdot D_{\text {AC }}
$$

The total drag of an aircraft is composed of the engine drag and the sum of any other drag component $D_{X}$ :

$$
D_{\mathrm{AC}}=D_{\text {eng }}+D_{X}=D_{\text {eng }}+0.91 \cdot D_{\mathrm{AC}}
$$

The wetted area of a conventional aeroengine is:

$$
A_{\text {wet }}=2 \cdot \pi \cdot r_{\text {eng }} \cdot z
$$

Here, $z$ is the length of the engine. In case of an integrated engine, the wetted area is reduced by the part marked with $S$ :

$$
\begin{aligned}
A_{\text {wet, int }} & =2 \cdot \pi \cdot r_{\mathrm{eng}} \cdot z \cdot\left(1-\frac{\lambda}{360^{\circ}}\right) \\
\lambda & =2 \cdot \arccos \left(1-\frac{h}{r_{\mathrm{eng}}}\right)
\end{aligned}
$$

The drag of the embedded engines can therefore be estimated with:

$$
D_{\text {eng, int }}=\frac{A_{\text {wet, int }}}{A_{\text {wet }}} \cdot D_{\text {eng }}=\frac{A_{\text {wet, int }}}{A_{\text {wet }}} \cdot 0.09 \cdot D_{\text {AC }}
$$

This leads to an equation for the calculation of the relative change in aircraft drag which equals the thrust at cruise conditions:

$$
\begin{aligned}
& D_{\mathrm{AC}, \text { int }}=D_{\text {eng, int }}+D_{X}=\frac{A_{\text {wet, int }}}{A_{\text {wet }}} \cdot 0.09 \cdot D_{\mathrm{AC}}+0.91 \cdot D_{\mathrm{AC}} \\
& \frac{D_{\mathrm{AC}, \text { int }}}{D_{\mathrm{AC}}}=\frac{A_{\mathrm{wet}, \text { int }}}{A_{\mathrm{wet}}} \cdot 0.09+0.91
\end{aligned}
$$

The engines of the EWL-BWB are embedded $0.33 \mathrm{~m}$ into the aircraft body and the radius is $0.95 \mathrm{~m}$. Hence, only $97.5 \%$ of the thrust with podded engines is required. With this information an advanced power saving coefficient (PSC + ), which takes the benefit of engine integration into account, can be determined. As mentioned above, the thrust requirement of the $\mathrm{BWB}$ is $13 \mathrm{kN}$ per engine. The thrust reduction due to embedded engines is yet included in this value.

Figure 14 shows the necessary propulsive power of an aeroengine without BLI for different thrust requirements. Because of the higher drag, conventional podded engines would increase the thrust requirement from $13 \mathrm{kN}$ to $13.33 \mathrm{kN}$, the difference in propulsive power is then about three percent. This power saving potential can be added to the PSC to get the PSC+ value. For the EWL-BWB the PSC+ is $5.4 \%$.
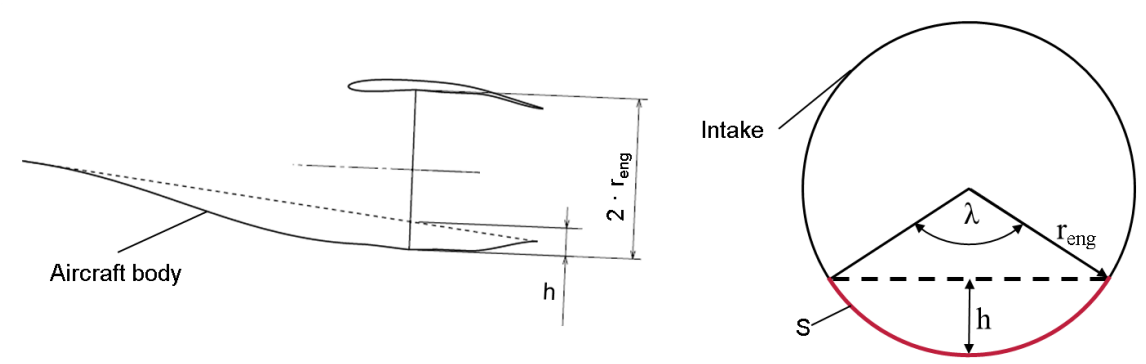

Figure 13. Side view of an embedded engine (left) and front view of the engine substitution model (right). 


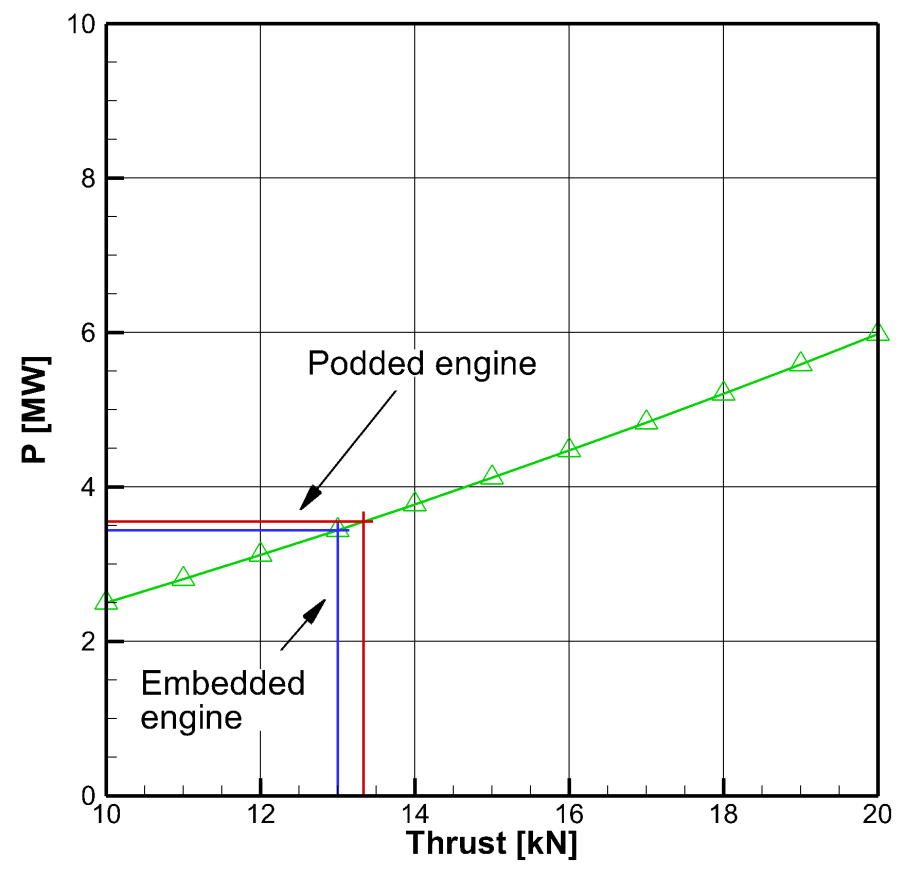

Figure 14. Propulsive power consumption without BLI effect.

\subsection{Further Investigations}

To get a deeper understanding of BLI, more sophisticated numerical investigations have been started. These ongoing CFD studies are not included since an elaborate thrust-drag-bookkeeping is necessary to isolate the BLI effect which would go beyond the scope of this paper. Due to this, a comparison of the preliminary results to experimental or CFD data is not possible at the moment but is recommended to be subject of future work.

\section{Conclusions}

To investigate asymmetric boundary layer ingestion, a tool based on a parallel compressor model is developed. The necessary boundary layer data is generated with XFOIL, a programme for the design and analysis of 2D subsonic airfoils, in order to get realistic results. In addition, the computation of the BLI benefit accounts for the cutback in fan efficiency caused by the non-uniform inflow. Subject of the study is the NASA SC(2)-0518 profile.

The results show a power saving coefficient of one to four percent depending on required thrust and flight altitude. For the preliminary design point (cruise) of the EWL-BWB, the PSC is $2.44 \%$. At this operating point the difference in fan efficiency between distorted and undistorted sector is about three percentage points. A variation of the fan radius reveals a slight influence on PSC. Increasing the radius by $0.05 \mathrm{~m}$ results in a PSC rise of approximately 0.2 percentage points. Finally, the drag reduction due to embedded engines is estimated and the PSC + is introduced. This quantity combines the drag reduction (expressed in terms of propulsive power saving) and the BLI benefit. The embedment of the EWL-BWB engines saves about three percent propulsive power so the PSC + is $5.4 \%$ at the preliminary design point.

Acknowledgments: We would like to acknowledge the support of the Ministry for Science and Culture of Lower Saxony (Grant No. VWZN3177) for funding the research project "Energy System Transformation in Aviation" in the initiative "Niedersächsisches Vorab". The authors also appreciate the assistance of Nils Beck who provided the boundary layer data. Furthermore, we acknowledge support by the German Research Foundation and the Open Access Publication Funds of the Technische Universität Braunschweig. 
Author Contributions: Nils Budziszewski developed the presented calculation tool, conducted the investigations and wrote the paper; Jens Friedrichs helped on procedure and results discussions and contributed to the paper preparation.

Conflicts of Interest: The authors declare no conflict of interest.

\section{Nomenclature}

\section{Latin}

A area

C profile depth

D drag

h depth of embedment

$\mathrm{H}$ altitude

$\dot{m}$ mass flow

Ma Mach number

$P \quad$ propulsive power

$r \quad$ radius

Re Reynolds number

$\mathrm{S}$ embedded surface

$T$ thrust

$\mathrm{u}_{\text {Tip }}$ circumferential fan tip velocity

$v \quad$ velocity

$x, y, z$ cartesian coordinates

\section{Greek}

$\alpha \quad$ angle of attack

$\delta$ boundary layer thickness

$\delta^{*} \quad$ displacement thickness

$\epsilon \quad$ angle of the distorted sector

$\eta \quad$ efficiency

$\lambda$ angle which describes the embedded part of an engine

$\theta \quad$ momentum thickness

$\pi$ pressure ratio

$\phi \quad$ substitute for compressor parameter, e. g. pressure ratio, efficiency

$\varphi \quad$ flow coefficient

\section{Indices}

$\begin{array}{ll}\text { AC } & \text { aircraft related } \\ \text { Asym } & \text { asymmetric } \\ \text { BL } & \text { quantity is related to boundary layer substitution model } \\ \text { BLI, no BLI } & \text { with/without boundary layer ingestion } \\ \text { dis } & \text { distorted sector } \\ \text { eng } & \text { engine related } \\ \text { E } & \text { boundary layer edge } \\ \text { ff } & \text { free flow sector } \\ \text { FA } & \text { full annular } \\ \text { Fan } & \text { fan related } \\ \text { in } & \text { inlet, inflow } \\ \text { int } & \text { integrated/embedded engine } \\ \text { is } & \text { isentropic } \\ \text { out } & \text { outlet, outflow } \\ \text { tt } & \text { calculated with total quantities } \\ \text { wet } & \text { wetted }\end{array}$


Abbreviations

$\begin{array}{ll}\text { BLI } & \text { boundary layer ingestion } \\ \text { BLIC } & \text { Boundary Layer Ingestion Calculator } \\ \text { BWB } & \text { blended wing body } \\ \text { ICAO } & \text { International Civil Aviation Organisation } \\ \text { PCM } & \text { parallel compressor model } \\ \text { PSC } & \text { power saving coefficient } \\ \text { PSC+ } & \text { advanced power saving coefficient }\end{array}$

\section{References}

1. European Commission. European Aeronautics: A Vision for 2020; European Commission: Luxembourg, 2001; ISBN 92-894-0559-7.

2. European Commission. Flightpath 2050 Europe's Vision for Aviation; European Commission: Luxembourg, 2011.

3. Steiner, H.-J.; Seitz, A.; Wieczorek, K.; Plötner, K.; Isikveren, A.T.; Hornung, M. Multi-Disciplinary Design and Feasibility Study of Distributed Propulsion Systems. In Proceedings of the 28th ICAS, Brisbane, Australia, 23-28 September 2012.

4. Plas, A. Performance of a Boundary Layer Ingesting Propulsion System. Master's Thesis, Massachusetts Institute of Technology, Cambridge, MA, USA, 2006.

5. Hardin, L.W.; Tillman, G.; Sharma, O.P.; Berton, J.; Arend, D.J. Aircraft System Study of Boundary Layer Ingesting Propulsion. In Proceedings of the 48th AIAA Joint Propulsion Conference AIAA 2012-3993, Atlanta, GA, USA, 30 July-1 August 2012.

6. Uranga, A.; Drela, M.; Greitzer, E.M.; Titchener, N.A.; Lieu, M.K.; Siu, N.M.; Huang, A.C. Preliminary Experimental Assessment of the Boundary Layer Ingestion Benefit for the D8 Aircraft. In Proceedings of the 52nd Aerospace Sciences Meeting, AIAA SciTech Forum AIAA 2014-0906, National Harbor, MD, USA, 13-17 January 2014, doi:10.2514/6.2014-0906.

7. Uranga, A.; Drela, M.; Greitzer, E.M.; Hall, D.K.; Titchener, N.A.; Lieu, M.K.; Siu, N.M.; Casses, C.; Huang, A.C.; Gatlin, G.M.; et al. Boundary Layer Ingestion Benefit of the D8 Transport Aircraft. AIAA J. 2017, 55, 3693-3708, doi:10.2514/1.J055755.

8. Smith, L.H., Jr. Wake Ingestion Propulsion Benefit. J. Propuls. Power 1993, 9, 74-82.

9. Lesser, A. Numerische Untersuchung von Axialverdichtern mit gestörter Zuströmung. Ph.D. Thesis, Universität der Bundeswehr München, Neubiberg, Germany, 2014.

10. Longley, J.P.; Greitzer, E.M. Inlet Distortion Effects in Aircraft Propulsion System Integration. Available online: https://ntrs.nasa.gov/search.jsp?R=19920019221 (accessed on 2 February 2018).

11. Grieb, H. Verdichter für Turbo-Flugtriebwerke; Springer: Berlin/Heidelberg, Germany, 2009; p. 460ff, doi:10.1007/978-3-540-34374-5.

12. Drela, M. XFOIL: An Analysis and Design System for Low Reynolds Number Airfoils. In Low Reynolds Number Aerodynamics, Proceedings of the Conference Notre Dame, Indiana, USA, 5-7 June 1989; Mueller, T.J., Ed.; Springer: Berlin/Heidelberg, Germany, 1989; pp. 1-12, ISBN-13 978-3-540-51884-6.

13. Giesecke, D.; Friedrichs, J.; Stark, U. Preliminary Aerodynamic Design of a Fan Stage for an Ultra High Bypass Ratio Engine. In Proceedings of the 23rd ISABE Conference, Manchester, UK, 3-8 September 2017.

14. Zhoujie, L.; Martins, J.R.R.A. Aerodynamic Design Optimization Studies of a Blended-Wing-Body Aircraft. J. Aircr. 2014, 51, 1604-1617, doi:10.2514/1.C032491.

15. Beck, N.; Landa, T.; Seitz, A.; Boermanns, L.; Yaolong, L.; Radespiel, R. Drag Reduction by Laminar Flow Control. Energies 2018, 11, 252, doi:10.3390/en11010252.

16. Hennies T. Erstellung eines Rechenmodells für den Triebwerkschub aus einer Kraftmessung innerhalb der Triebwerksaufhängung. Bachelor's Thesis, TU Braunschweig, Braunschweig, Germany, 2017. 